Session ETD 525

\title{
Engineering Technology Capstone Projects
}

\author{
Walter W. Buchanan \\ Texas A\&M University
}

\section{Introduction}

Most four-year institutions that have an engineering technology program end it with a capstone sequence. This usually includes a course in each of the last two semesters that first cover the fundamentals of technical project management with planning and approval activities necessary to prepare a technical proposal including the scope of technical design project that will be done during the final semester. A team approach is usually used to analyze and design a basic industrial level project using standard components and proven design techniques. This session will give presentations with examples of how programs from around the country have done this.

\section{Capstone Final Project Implementation and Assessment}

The students at Youngstown State University are required to complete two courses, Specifications and Estimating (CCET 3711) and Hydraulics and Land Development (CCET 3724) at the end of the associate's program. Professor Sanson instructs the Specifications and Estimating course and Professor Korenic instructs the Hydraulics and Land Development course and have combined the final project of these two courses into a mini capstone. Here will be described how the mini-capstone project has been developed, the instruction the students receive in each of the courses, how the students implement the instruction in the capstone project, and the components that make up the project. The outcomes that are detailed and assessed in this paper are based on student performance and pertain to how well the students work as a team. Also assessed are how well each student was able to implement concepts learned in each class, which include estimating various aspects of a real construction project as well as their ability to determine the storm water volume quantities, specify erosion and sedimentation control measures, and design an appropriate storm water detention structure. The culminating event of the project is a professional oral presentation in which the students compile their findings of each aspect of the mini-capstone project [1].

\section{Complex Modeling for Feed Forward Control Systems for Furnace Temperature Optimization}

Simulink PLC Coder extension for MathWorks Simulink modeling software provides a novel approach for designing and exporting complex controls systems for PLCs and PACs. The senior design team utilized the software to better optimize furnace controls in a feed forward system for our industrial sponsor. This report will reflect on the process of using PLC coder to model and create IDE-specific structured text code for the furnace control system. The coder extension 
allows the user to build a complex system model in Simulink, including mock-ups of the controls and plant. Simulink can verify operation through simulation and built in diagnostics. After the model is verified the controls system can be isolated and PLC Coder can generate PLC code from it for multiple target IDEs. The resulting code will be commented and tagged to assist in the ease of integration within an existing system. This process will greatly reduce the time for delivery of complex controls systems for industrial PLC applications [2].

\section{Experimental Investigation of Condenser Shading Effects on Residential Air Conditioning Unit Performance}

Condensers are used in chillers and air-conditioning systems to reject heat from the refrigerant to the outdoor air. Blocking the solar flux radiated from the sun and hitting the condenser is expected to improve the performance of the air-conditioning system. To investigate this concept, a team of three mechanical engineering technology students shaded a three-ton residential air conditioning unit and logged the condenser and evaporator temperatures to evaluate the coefficient of performance (COP) of the cycle under various outdoor temperature conditions. The team logged the temperatures across the condenser and the evaporator temperature while the condenser was being shaded and unshaded for thirty days with each condenser state. The evaporator was maintained at three different temperatures of $41^{\circ} \mathrm{F}, 46.3^{\circ} \mathrm{F}$, and $50^{\circ} \mathrm{F}$. Averages of the COP were grouped per outdoor temperatures and were compared for shaded versus unshaded cases. Outdoor temperatures ranged between $65-88^{\circ} \mathrm{F}$. The results showed 2-39\% improvement in the COP of the cycle under various evaporator temperatures. The project was assessed through biweekly progress reports, presentations, final report and teamwork that satisfied many of the ABET outcomes [3].

\section{Bibliography}

[1] Sanson, J., "Capstone Final Project Implementation and Assessment," Proceedings 2020 ASEE Conference for Industry and Education Collaboration, pp. 525201-208, Orlando, Florida, January 2020.

[2] Price, T., Poel, S., and Sergeyev, A., “Complex Modeling for Feed Forward Control Systems for Furnace Temperature Optimization,” Proceedings 2020 ASEE Conference for Industry and Education Collaboration, pp. 525501-508, Orlando, Florida, January 2020.

[3] Shehadi, M., "Experimental Investigation of Condenser Shading Effects on Residential Air Conditioning Unit Performance,” Proceedings 2020 ASEE Conference for Industry and Education Collaboration, pp. 525601-609, Orlando, Florida, January 2020. 